\section{Compreensões integradas para a vigilância da saúde em ambiente de floresta: o caso da Chapada do Araripe, Ceará, Brasil}

\author{
Integrated understanding for health surveillance \\ in a forest environment: the case of the Araripe \\ Plateau in Ceará State, Brazil
}

\author{
${ }^{1}$ Centro de Pesquisas Aggeu \\ Magalhães, Fundação \\ Oswaldo Cruz, Recife, Brasil. \\ 2 Fundação Araripe, \\ Crato, Brasil. \\ ${ }_{3}$ Casa Lilás, Crato, Brasil. \\ Correspondência \\ L. G. S. Augusto \\ Departamewnto de Saúde \\ Coletiva, Centro de Pesquisas \\ Aggeu Magalhães, Fundação \\ Oswaldo Cruz. \\ Av. Professor Moraes Rego s/n, \\ Cidade Universitária, Recife, \\ PE 50670-420, Brasil. \\ giraldo@cpqam.fiocruz.br
}

\begin{abstract}
Partial results from this study are presented with the objective of developing a health surveillance model for communities living on natural resources in the Araripe National Forest in Ceará State, Brazil. The research is justified primarily on the basis of this forest's importance for quality of life in Northeast Brazil and preservation of the country's forests in general. The study drew on a collective construction of integrated understanding on the subjectivity of social relations with the environment. Social and environmental health problems in the forest context have generally been overlooked by health policy.
\end{abstract}

Population Surveillance; Environmental Health; Ecosystem
Lia Giraldo da Silva Augusto 1

Lourdes Góes 2,3

\section{Introdução}

Conhecer os processos sócio-ambientais em contextos de florestas é fundamental para um país que possui enormes reservas naturais terrestres de flora, as quais estão permanentemente sob pressão, especialmente em face do avanço das fronteiras agrícolas ou da urbanização de seu entorno, afetando os diferentes biomas e criando nocividades para os povos de dentro e de fora das florestas, os quais dependem destas para sobreviver.

Este trabalho representou um esforço de uma rede sócio-institucional da qual participaram: a Fundação Araripe, a Coordenação Geral de Vigilância em Saúde Ambiental do Ministério da Saúde, o Centro de Pesquisas Aggeu Magalhães da Fundação Oswaldo Cruz, Sindicatos de Trabalhadores Rurais, a entidade feminista Casa Lilás e a Fundação Lima Botelho do Município de Jardim no Estado do Ceará.

A percepção das populações tradicionais, que obtêm sua subsistência na Floresta Nacional do Araripe, é fundamental na descrição e na análise dos contextos sócio-econômicos e políticos que integram informações técnico-científicas e da tradição. As duas dimensões se retroalimentam, permitindo o olhar para complexidade da vida humana. Contemplam, ao mesmo tempo, as questões relacionadas às bases materiais e às bases afetivas na construção das identidades coletivas e individuais, relativas às representações 
que essas populações têm acerca da saúde, do ambiente e das relações estabelecidas entre eles, no que se refere à afirmação do sujeito coletivo.

Estudar essa questão a partir da ótica da complexidade requereu buscar compreender as conexões existentes entre saúde, processo produtivo e ambiente. Nesse sentido, buscou-se romper com a abordagem que trata a lógica da natureza separadamente da social, buscando uma perspectiva integradora 1,2 .

Consideraram-se, na abordagem pretendida, as diferenças e desigualdades de gênero. Para a perspectiva deste projeto, o ambiente é tudo, sejam as realidades materiais exteriores ao ser humano, sejam aquelas que ele mesmo criou e transformou. Homem e mulher são, igualmente, partes da natureza, e com ela estão em permanente ligação. Para dar conta de tal objeto com base em um enfoque ecossistêmico da saúde e da qualidade de vida, foram considerados, neste trabalho, os conceitos subjacentes aos processos da saúde, do ambiente, do território, da biodiversidade da floresta, da sustentabilidade, da preservação, do extrativismo, da relação Ser Humano-Floresta.

Segundo Minayo 2, a interação entre ser vivo e o ecossistema é absolutamente necessária. O enfoque ecossistêmico da saúde e da qualidade da vida representa uma possibilidade de superar o paradigma dominante antropocêntrico, relacionando-se com vários aspectos no campo da sustentabilidade ecológica: a democracia, os direitos humanos e a justiça social ${ }^{3}$. A reflexão sobre desenvolvimento e sustentabilidade, por sua vez, passa a ser fundamental para compreender a dimensão ecossistêmica da saúde 4,5 . Portanto, foi importante observar a relevância da categoria "lugar" como espaço organizado para análise e intervenção na realidade, buscando identificar as relações entre saúde e seus condicionantes sociais, culturais, econômicos, políticos e ambientais, dentro dos ecossistemas modificados pelos processos produtivos e suas tecnologias 6 .

Segundo Tambellini \& Câmara 1 , a questão da saúde tem relação com o ambiente e com a produção, relações entendidas a partir da lógica da natureza e da lógica da sociedade, que vai configurar o espaço socialmente modificado onde se processam todas as relações humanas.

A compreensão abrangente de vigilância da saúde, além de englobar as dimensões biológicas, sociais, psíquicas e ecológicas, também articula o indivíduo (no qual se manifesta a doença) e o coletivo (no qual se traduz o processo saúdedoença) 7 .

A análise da saúde requer um olhar sobre o conjunto de seus determinantes e condicionantes históricos, genéticos, biopsíquicos, sociais e ecológicos/ambientais 8. A interação desses elementos é que determina sua particularização, sendo uma decorrência dinâmica de fatores promotores e agressivos sobre o indivíduo e/ou a coletividade 4 .

A vigilância da saúde comporta, por sua vez, ações nos vários níveis de prevenção ${ }^{9}$. As estratégias específicas, de acordo com a situação de saúde das populações, em cada território, incluem a busca de superação das desigualdades sociais. É nesse sentido que a construção de indicadores operativos tem grande relevância 10 .

O processo de transformação de matériasprimas em outros produtos para o atendimento das necessidades e desejos humanos parece inevitável e absolutamente necessário. No entanto, o uso da natureza como se fosse uma fonte inesgotável de recursos deve ser urgentemente revista à luz da crise ambiental que está ameaçando a própria vida das populações locais e do planeta 11 .

A referência do desenvolvimento sustentável, que objetiva deter e reverter a degradação dos ecossistemas, bem como superar as brutais desigualdades entre os países e no seio das sociedades nacionais, deve ser uma tese condutora de vigilância da saúde.

A região do Cariri, localizada ao Sul do Estado do Ceará, tem sua geografia marcada pela Chapada do Araripe, com uma área de proteção ambiental e uma floresta nacional. Conta com mais de oitenta municípios na chamada mesorregião do Araripe, compreendendo, além do Estado do Ceará, os Estados do Piauí, Pernambuco e Paraíba, sendo as cidades de Crato, Juazeiro do Norte e Barbalha o seu centro de desenvolvimento político e econômico ${ }^{12}$. Considerado um pólo da cultura cearense, o Cariri é rico na diversidade de suas manifestações sócio-culturais, merecendo destaque as danças (reisado e maneiro-pau), as artes plásticas (esculturas, pinturas e xilogravuras), a música (cantorias) e, com destaque, a literatura de cordel. Na Chapada do Araripe, com área de $55.000 \mathrm{~km}^{2}$, a exploração de recursos energéticos oriundos de madeira se dá sem manejo adequado; em poucas décadas, teve sua cobertura florestal reduzida em 50\% 12,13.

Os brejos da Região Nordeste do Brasil são disjunções da floresta tropical perenifólia dentro da zona da caatinga. O maior de todos está no Cariri cearense, formação natural da Chapada do Araripe, com um grande reservatório de água no subsolo que serve aos três estados fronteiriços: Ceará, Pernambuco e Piauí.

A Chapada do Araripe abriga um espaço com um bioma de características geológicas, geomorfológicas, pedológicas, climáticas, hidrográficas / hidrológicas e de vegetação bem diversificado. 
Faz parte dos condicionantes ecológicos de uma área com importância fundamental, tanto para a identificação dos processos evolutivos da Terra, por seus sítios paleontológicos, como para a sobrevivência das populações que dela tiram seu sustento e dos que vivem em seu entorno. Existe uma relação entre a Chapada do Araripe e outros ecossistemas brasileiros que repercute nas modificações climáticas, nas expansões e contrações de formações florestais, nas modificações da composição da fauna e flora, o que tem sido objeto de debates sobre biodiversidade nos últimos trinta anos 12 .

Outra relação importante é a que se dá entre o desenvolvimento regional e esses recursos florestais, que geram cerca de 170 mil empregos diretos e 500 mil indiretos. A lenha responde por $70 \%$ da demanda energética dos domicílios da região e $35 \%$ do parque industrial da região ${ }^{12}$. A floresta é o elemento natural que define e mantém a qualidade ambiental, a conservação dos aqüíferos, a beleza cênica, o sistema agropecuário tradicional (pecuária extensiva e agricultura de subsistência) e a conservação dos solos dessa região 12 .

As formações florestais da Chapada do Araripe podem, de maneira simplificada, ser estratificadas em mata úmida, cerradão, cerrado, carrasco e caatinga.

A produção florestal é absorvida também pelos produtores rurais para atender necessidades de infra-estrutura dentro das propriedades (entre outras, cercas, construções rurais, cabo de ferramentas agrícolas e portais), representando uma atividade complementar às atividades agropecuárias nos períodos de estiagem no semi-árido nordestino.

Além do potencial madeireiro, também há a produção de frutos e produtos obtidos de espécies consideradas não madeireiras, tais como: araçá (Psidium araça Raddi), cajuí (Anacardium humile), pitanga (Eugenia michelli), pequi ( $\mathrm{Ca}$ ryocar coriaceum), janaguba (Himatanthus drasticu), faveira (Dimorphandra gardneriana), jatobá (Hymenaea stignocarpa) e pau de óleo ou copaíba (Copaifera langsdorffii), que apresentam valor econômico e cultural para a região ${ }^{12}$.

Essa riqueza mostra a necessidade de se estabelecerem mecanismos de gestão condizentes com as necessidades das famílias, principalmente as de baixa renda, as quais estão adaptadas aos ciclos dos frutos da floresta como alternativa para a falta de trabalho formal. Trata-se de uma atividade produtiva, que faz parte dos mecanismos de absorção de mão-de-obra, sendo importante para a economia na região da Chapada do Araripe.

Para toda essa estratificação, o uso da vegetação deveria ser de forma ordenada e sustentada através de técnicas de manejo adequado ao local, respeitando as áreas de preservação permanente, resguardando-se boa parte das espécies para preservação de sementes.

Assim, considerando-se o contexto sócioambiental da Chapada do Araripe, os objetivos centrais do estudo foram compreender as relações sociais decorrentes das interações de grupos humanos com o ambiente de floresta em face do processo produtivo extrativista vegetal e identificar os decorrentes problemas ambientais e sociais, que são importantes para orientar ações de vigilância da saúde.

\section{Método}

Foram selecionados dois municípios cearenses de onde procede a parte significativa dos grupos humanos extrativistas da floresta do Araripe: Crato (113.497 habitantes), com predominância de características urbanas, e Jardim (27.671 habitantes), com predominância de características rurais. O estudo ocorreu no período de 2004 a 2005.

Para o presente artigo, serão apresentados os aspectos da abordagem qualitativa que foi realizada mediante observação participante e grupos focais. O aspecto descritivo e exploratório do estudo é importante por se tratar de uma realidade ainda pouco estudada, com resgate históricocultural e das representações sociais no contexto de vida. A participação dos sujeitos envolvidos na problemática estudada foi fundamental para a investigação realizada.

Para iniciar o estudo, foram realizados dois seminários de apresentação e discussão de seus objetivos e método. Nestas oportunidades, foram esclarecidas dúvidas e escolhidos os informantes-chave para formar grupos com representação das principais organizações e associações presentes. Também foram escolhidos os interlocutores locais e elaborado o cronograma das reuniões dos grupos focais.

Tomou-se como referencial teórico-metodológico a proposta pedagógica do educador Paulo Freire.

Tendo como base depoimentos de lideranças locais, foram identificados diversos temas geradores, que foram analisados e agrupados por afinidade, complementados por dados secundários da literatura e da observação participante, formando-se blocos temáticos centrais. Estes deram origem às figuras geradoras (desenhos ilustrativos, ver um exemplo na Figura 1), que expressam o cotidiano das comunidades, para facilitar "a leitura do mundo" com criticidade e auxiliar o desvelamento da realidade. 
Figura 1

Problemática relativa à fiscalização do Instituto Brasileiro do Meio Ambiente e dos Recursos Naturais Renováveis (IBAMA) em face do corte de madeira.

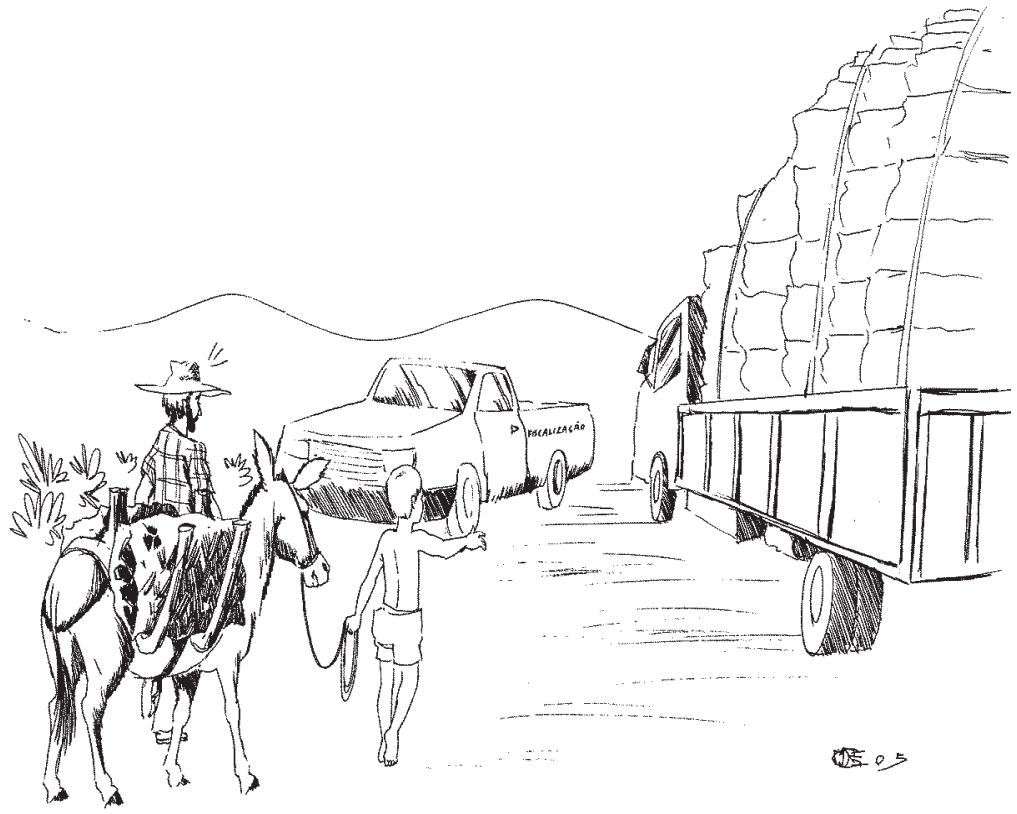

"O IBAMA chega lá pega os machados, as bicicletas dos pobres trabalhadores que vão trabalhar no plano que tá fechado, às vezes até sem saber que ali tá fechado" (F., mulher, grupo de mulheres de Jardim).

As figuras geradoras foram apresentadas ao grupo inicialmente, quando se perguntava: " $O$ que vocês estão vendo nessa figura? Que relação essa figura tem com a realidade de vocês? Que relação tem com a saúde?".

O mediador teve o papel de iniciar as sessões explicando os objetivos do projeto, de animar o debate, de orientar as questões e fazer as sínteses em consenso com o grupo. Os grupos focais iniciaram com o aceite individual do termo de consentimento esclarecido.

Os interlocutores-chave foram selecionados levando-se em consideração a representatividade existente nas comunidades; a diversificação destes por raça, etnia, sexo (masculino ou feminino) e idade (várias faixas etárias); nível educacional; envolvimento direto em atividades de exploração, comercialização e beneficiamento dos produtos florestais; moradia próxima de nascente de água; trabalho de fiscalização florestal, de vigilância da saúde, de monitoramento e de educação ambiental.
Foram compostos dois tipos de agrupamentos. Um de extrativistas, que foi dividido em subgrupos (de mulheres, de homens e misto) com 14 pessoas em cada um, e outro de técnicos/lideranças comunitárias, composto por 20 pessoas.

A separação do grupo de trabalhadores em grupos homogêneos por sexo objetivou assegurar a apreensão das percepções sobre o significado das questões, sem a inibição provocada pela presença de pessoas de outro sexo no grupo. Nos grupos mistos, o aprofundamento das mesmas questões se deu a partir do confronto de percepções, concepções e vivências distintas segundo o gênero.

O material coletado em cada grupo passou por um estágio de transcrição das fitas, agrupamento nas categorias de análise e, por fim, ordenamento dos problemas considerando diferentes níveis de complexidade.

As categorias de análise que serviram para agregar as falas dos grupos focais, entrevistas e observação dos pesquisadores foram ação governamental, cuidado com o meio ambiente, gestão de recursos hídricos, extrativismo, geração de renda, exploração do trabalho, queixas de saúde e relações de gênero.

\section{Resultados}

Observa-se que todas as categorias de análise são fundamentais para o processo de reprodução social dessa população. Destacamos, para discussão, alguns aspectos relevantes que ilustram a interdependência desses componentes e que apontam para a necessidade de uma abordagem integrada e contextualizada da saúde dos extrativistas. A Tabela 1 sintetiza os principais problemas identificados por categoria.

\section{Ação governamental}

Dentre as temáticas debatidas, a preocupação com o papel do Instituto Brasileiro do Meio Ambiente e dos Recursos Naturais Renováveis (IBAMA) no controle dos impactos ambientais causados pelas diversas formas de uso dos recursos naturais existentes na floresta foi muito enfatizada pelos participantes.

Há divergência de opinião entre os representantes do IBAMA e os das comunidades no que diz respeito à sustentabilidade do extrativismo na Floresta Nacional do Araripe. Estas acusam o órgão de não fornecer informações e de realizar apreensões e aplicação de multas apenas para o pobre. Os relatos expressam uma precária situação de vida e pobreza das populações da floresta, 
Problemas segundo as categorias de análise.

\begin{tabular}{|c|c|}
\hline Categorias de análise & Problemas \\
\hline Ação governamental & 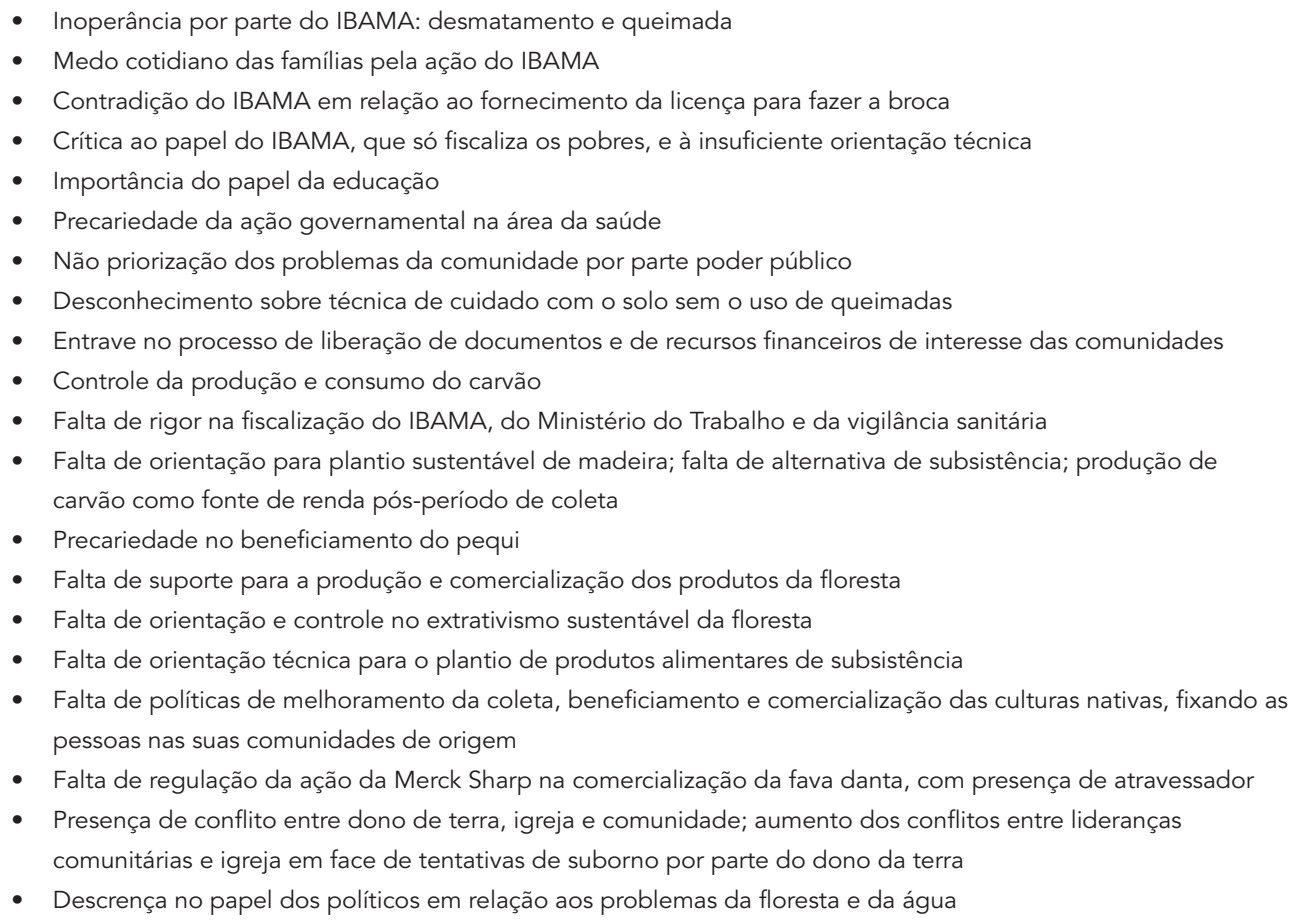 \\
\hline Gestão dos recursos hídricos & $\begin{array}{l}\text { - Efeito da privatização das águas das nascentes, dificultando o acesso a esse recurso } \\
\text { - Disputa pela água; violência } \\
\text { - Luta pelo acesso à água } \\
\text { - Água como recurso de geração de renda para a população } \\
\text { - Experiência coletiva de cuidado e conservação das nascentes } \\
\text { - Privatização e mau uso das terras no entorno das fontes } \\
\text { - Águas cedidas por "telhas" (medida oriunda do tempo colonial) - cada dia um dono de terra é beneficiado; } \\
\text { ameaça por parte dos donos/medo da população }\end{array}$ \\
\hline Cuidados com o meio ambiente & $\begin{array}{l}\text { - Desconhecimento por parte dos usuários das nascentes sobre os riscos ambientais à saúde por contaminação } \\
\text { - } \text { ou falta da água } \\
\text { - Lixo na floresta } \\
\text { - Falta de orientação sobre a floresta e de consciência de preservação } \\
\text { - Falta de orientação no manejo sustentável, falta de cuidado com a natureza } \\
\text { - Preocupação com o meio ambiente restrita a poucos interessados } \\
\text { - Pouca experiência com educação ambiental } \\
\text { - Falta de controle ambiental no processo do extrativismo } \\
\text { - Insuficiente experiência com cuidado e conservação da floresta } \\
\text { - Diminuição da vazão das fontes em conseqüências do desmatamento } \\
\text { - Falta de consciência ambiental por parte da maior parte da população, com redução das safras }\end{array}$ \\
\hline Extrativismo & $\begin{array}{l}\text { - Potencialidades da chapada não devidamente exploradas } \\
\text { - Extrativismo predatório } \\
\text { - Expectativa de exploração comercial dos produtos tidos como medicamentosos }\end{array}$ \\
\hline Exploração do trabalho & $\begin{array}{l}\text { - Presença de crianças e adolescentes no extrativismo e na produção de carvão } \\
\text { - Falta de acompanhamento no desenvolvimento do PETI }\end{array}$ \\
\hline
\end{tabular}

(continua) 
Tabela 1 (continuação)

\begin{tabular}{|c|c|}
\hline Categorias de análise & Problemas \\
\hline Saúde & 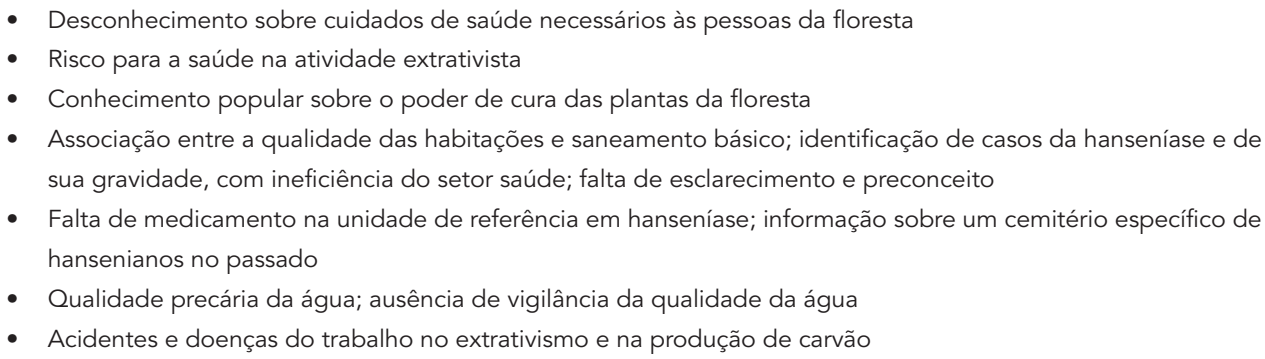 \\
\hline Relações de gênero & $\begin{array}{l}\text { - Inferiorização e discriminação da mulher com relação ao homem e violência } \\
\text { - Valores culturais que discriminam a participação de mulheres na vida comunitária } \\
\text { - Desemprego - as mulheres tornam-se empregadas domésticas; queixa de assédio sexual } \\
\text { - Sobrecarga de trabalho para as mulheres portadoras de água por longas distâncias }\end{array}$ \\
\hline
\end{tabular}

IBAMA: Instituto Brasileiro do Meio Ambiente e dos Recursos Naturais Renováveis; PETI: Programa de Erradicação do Trabalho Infantil.

as quais se utilizam da exploração desta para sobreviverem.

Os conflitos são entendidos como decorrência da insuficiência das atividades produtivas para sobrevivência das famílias, o que leva à exploração de recursos na área de proteção ambiental que integra a Floresta Nacional. De acordo com alguns técnicos, as precárias condições de funcionamento das instituições interferem na realização de uma ação mais sistemática e efetiva, comprometendo a qualidade do trabalho.

Observou-se nitidamente uma contraposição entre a posição dos técnicos do IBAMA e a dos representantes das comunidades. Conforme se pode verificar nos depoimentos, as alegações dos servidores foram de interferência dos políticos locais no bom desempenho institucional, em contraposição aos questionamentos colocados pelos populares, que afirmaram que existem deficiências na comunicação das informações que deveriam ser repassadas pelo IBAMA.

$\mathrm{Na}$ produção de carvão, não foi referida a existência de fiscalização ou avaliação das condições de produção por parte do setor do trabalho ou da saúde. A única fiscalização citada foi a do IBAMA, que se restringe a coibir o corte indevido de madeira e a queimada.

A ausência de políticas públicas de apoio aos catadores de pequi foi exemplificada pela falta de condições de armazenamento, de preço mínimo, de incentivo à organização e coletivização da produção.

\section{Gestão dos recursos hídricos}

A prioridade das águas na região não é para o consumo humano, havendo privilégios por parte dos proprietários que adquiriram as terras com o direito exclusivo de uso das fontes, baseando-se em um decreto muito anterior à legislação atual (Decreto $n^{o} .24 .643$ de 1934).

De acordo com o que ficou estabelecido na declaração ministerial, aprovada em Haia, em 2000, “o acesso de qualquer pessoa a água segura e suficiente, a um custo compatível com manutenção de uma vida produtiva e saudável", é um direito 13. Contudo, as comunidades do entorno e do topo da Chapada desconhecem esse direito, que também está garantido na Lei Nacional de Recursos Hídricos 14, que institui a Política Nacional de Recursos Hídricos e cria o Sistema Nacional de Gerenciamento de Recursos Hídricos. A lei disciplina o uso das águas das bacias hidrográficas de forma racional, com prioridade para o consumo humano, com a gestão democrática das águas por meio da criação de comitês de bacia, caracterizando a sociedade civil como componente fundamental do processo de gestão dos recursos hídricos (art. 1, inciso VI). Compreende também normas de garantia da tutela civil (indenização por danos), penal (responsabilidade criminal) e administrativa (multas e concessões de outorgas) em matéria de águas.

No entanto, a Política Nacional de Saneamento e Habitação, recentemente aprovada, ainda requer implementação e, sem esta, não há garantias para o provimento de água potável nem a segurança de que, em situações de escassez, o uso prioritário dos recursos hídricos seja, de fato, para o consumo humano e a dessedentação de animais (art. 1, inciso I), entendendo-se tais recursos como um bem de domínio público (art. 1 , inciso III). 
Existem representantes de comunidades que detêm melhor informação sobre a importância da água para a preservação da saúde, bem como já constataram que existe risco real de desabastecimento, uma vez que se observa o desaparecimento de diversas fontes em curto espaço de tempo.

\section{Cuidado com o meio ambiente}

A qualidade ambiental da região foi um ponto que gerou posições contraditórias entre os grupos. Em alguns momentos foi notória a associação entre saúde e ambiente, especialmente a associação entre queimadas e problemas respiratórios. Também explicitaram a preocupação com o desequilíbrio ecológico como decorrência da falta de alternativa para sobrevivência das famílias.

Apareceram as visões fatalistas, religiosas, atribuindo a Deus a proteção contra as doenças e agravos decorrentes da falta de condições de moradia. Observou-se também que existe ainda desconhecimento sobre o impacto das condições de saneamento, em particular o relativo ao lixo, sobre a qualidade de saúde da população e sua implicação com o aparecimento de pragas nocivas à saúde.

As formas inadequadas de uso das fontes de água para a grande parte do grupo é um fator que contribui para a degradação ambiental, dificultando a melhoria das condições de saúde e de vida.

As queimadas para produção de pastagens foram relatadas como prática comum, que provocam o desmatamento junto às fontes. Este tema foi apontado como um problema que poderá causar, no futuro, prejuízo na produção dos aqüíferos, comprometendo o equilíbrio ambiental e a saúde da população.

\section{Extrativismo}

A atividade extrativista do pequi é reconhecida como uma atividade penosa. Ressaltaram-se as possibilidades de seu beneficiamento - fabricação do óleo -, que poderia complementar o trabalho na pós-colheita, sendo mais uma fonte de renda.

Na produção de carvão vegetal, os problemas foram identificados desde a retirada da madeira, seja nos planos de manejo, seja em área de proteção, até a realização do processo final da produção para sua obtenção. Esta atividade, para os que vivem da floresta, representa uma das poucas possibilidades de geração de renda no período entressafra da agricultura e da coleta de frutos.
Neste processo, três aspectos chamaram a atenção: os instrumentos rudimentares utilizados para coleta, que danificam árvores, com a quebra de galhos; a insegurança no trabalho, pela forma como praticam a coleta e por não terem instrumentos adequados (ao subirem nas árvores, com freqüência ocorrem quedas com traumas físicos); pelo mercado na cadeia de comercialização da fava danta. Por se tratar de uma planta que apresenta alto teor de uma substância anticoagulante, tem valor comercial para indústria de medicamentos. Existem atravessadores que compram esses produtos in natura a baixo preço para a empresa alemã Merck, que, por ser a única compradora, detém o monopólio da comercialização, submetendo os coletores a condições aviltantes.

De acordo com o conhecimento popular, a seiva da janaguba cura várias enfermidades (ferimentos, úlceras, gastrite, câncer e problemas de circulação sanguínea). A forma de coleta da janaguba, com freqüência prejudica a vitalidade das árvores.

\section{Exploração do trabalho}

Todos os produtos coletados no extrativismo apresentam, no processo de comercialização, aviltamento dos preços e uma superexploração do trabalho pelos atravessadores.

Na época da safra do pequi, toda a família é envolvida, embora haja por parte de alguns pais a preocupação com o trabalho infantil, reconhecendo que é algo ilegal e que prejudica as crianças, pois as expõe aos riscos, como picadas de cobras, atrapalhando a inserção delas nos estudos. No entanto, afirmam não poder dispensar a mão-de-obra infantil.

Existem problemas semelhantes em outros locais do país. A sua constatação na população extrativista indica a necessidade de sua priorização no sistema de vigilância à saúde. O Instituto Brasileiro de Geografia e Estatística (IBGE), em 1990, revelou que 7,5 milhões de brasileiros entre 10 e 17 anos trabalhavam, representando $11,6 \%$ da força de trabalho do país, e que 3,5 milhões têm menos de 14 anos, dos quais 2,7 milhões estão fora da escola. Trata-se de uma mão-de-obra desorganizada, dócil e barata. Em $70 \%$ dos casos, recebiam em média meio salário mínimo e, em muitos casos, cumpriam jornadas de até 12 horas diárias de trabalho, principalmente os que atuavam em ambientes altamente insalubres, como carvoarias, fábricas de sapato, canaviais e outras plantações 15. O importante Programa de Erradicação do Trabalho Infantil do Governo Federal ainda não chegou à Chapada do Araripe. 
Quando se tratou da mão-de-obra de adolescentes, foi manifestada uma preocupação, principalmente por parte das mulheres, sobre o seu futuro. Nas comunidades, os jovens não têm o que fazer e a ociosidade os expõe ao uso do álcool, propiciando atitudes marginais, expondo-os à violência. A prostituição e a gravidez precoce das adolescentes foram relatadas como um grande problema para as famílias.

Embora possa ser bastante prejudicial, a participação de crianças no trabalho doméstico e no extrativismo, muitas vezes em idade bastante precoce, é uma prática muito comum e bem aceita no local. A carga de trabalho é, geralmente, pesada, repercutindo negativamente no rendimento escolar. Por acontecer em ambiente privado, de certo modo ocultado, este é um tema difícil de ser objeto de ações públicas, o que não significa que não deva ser atendido.

Foram citados, ainda, outros problemas, como a falta de segurança, o desamparo trabalhista e a prostituição de menores. Os acampamentos funcionam como um "território sem lei", nos quais a superlotação na busca de condições de trabalho e sobrevivência faz com que muitas famílias fiquem aglomeradas sem condições de infra-estrutura e de convivência humanizada.

\section{Saúde}

Observou-se que existe uma visão mitificada dos benefícios que o pequi traz para a população da floresta. Consideram que o fruto tem alto valor nutritivo e é eficaz para a cura de vários problemas de saúde.

As comunidades das áreas que produzem carvão relataram que as más condições de trabalho (a exposição a altas temperaturas, à fumaça produzida na queima da madeira e a falta de equipamentos de proteção individual - EPI) são responsáveis pelos agravos na saúde como: " $t u$ berculose, magreza excessiva e intoxicações”. As queixas relacionadas a problemas respiratórios nas áreas de maior produção de carvão foram comuns.

Relata-se que há locais em que a mão-deobra infantil é utilizada para retirar o carvão de dentro dos fornos, uma vez que o espaço de abertura da caieira é pequeno. Ali, ficam expostas diretamente ao calor intenso, à fumaça e aos gases, ocorrendo em alguns casos queimaduras.

Há boa percepção da nocividade dessa atividade na saúde das crianças, no entanto verificouse a presença de grande quantidade delas envolvidas nas várias etapas do processo produtivo. As crianças são levadas para a broca no intuito de oferecerem ajuda aos pais, tarefa considerada leve e fácil.
Além dos problemas de saúde foram citadas dificuldades de conciliação do trabalho infantil com os estudos, sendo esta responsável pelo alto índice de evasão escolar das crianças no período de produção de carvão e da coleta de frutos.

$\mathrm{O}$ transporte de água pelas mulheres e crianças é ainda uma prática comum, conforme foi observado e referido. Em geral, essas pessoas percorrem grandes distâncias levando, na cabeça, vasilhas de água ou trouxas de roupas para lavar. Há queixas de agravos osteomusculares que acometem sobretudo mulheres e que foram atribuídos ao excesso de peso que os trabalhadores transportam.

Uma questão bastante enfocada pelos informantes foi relativa às condições sanitárias na comercialização do pequi, sendo relatada a ausência e/ou precariedade do papel da vigilância sanitária.

\section{Relações de gênero}

Em relação ao trabalho infantil, um aspecto observado foi o caráter dual na representação de gênero por parte das famílias. É fato a consideração de que cabe ao homem o sustento da família através do trabalho dito honesto, o que é cobrado dos meninos. A função masculina de provedor foi fortemente associada às idéias de masculinidade e de reprodutor dos padrões de comportamento de gênero vigentes. Não foram feitas, entretanto, alusões ao trabalho realizado pelas meninas. O trabalho das mulheres foi tido como um dificultador para os cuidados da família, em especial das crianças, como agravante de sua situação.

\section{Conclusões}

Compreende-se que a proposta de vigilância da saúde para os grupos humanos que vivem da floresta no contexto da Chapada do Araripe deve ser formulada para mudanças efetivas nas condições das nocividades identificadas. Tal proposta deve recuperar a relação saudável do ser humano com a natureza, que só poderá acontecer mediante políticas públicas estabelecidas com essa intencionalidade.

As más condições em que se opera a atividade extrativista; a dificuldade de acesso à água potável; a inexistência de infra-estrutura de saneamento; o precário acesso a serviços de saúde, que inclui a baixa cobertura da atenção à saúde, e a desestruturação das famílias tornam essa população vulnerável e apontam para um grave problema de saúde pública nesse contexto. Destaque-se o processo de produção de carvão, 
pelos problemas respiratórios referidos e pelas várias formas de violência sobre as crianças e os adolescentes, cuja marca está na exploração do trabalho infantil e na impossibilidade de acesso à escola. O extrativismo vegetal e as condições das nascentes são questões em que o setor ambiental deveria atuar com prioridade.

Em relação às mulheres, concluímos que a vida delas é marcada pela desigualdade de gênero, pela violência nas suas mais diversas manifestações. Esse processo em relação às meninas se expressa de uma forma ainda mais cruel, na manifestação da gravidez na adolescência e na violência sexual. Quanto aos aspectos comportamentais dos homens, destaca-se o alcoolismo, a violência e o machismo, produzindo vulnerabilidades diferenciadas.

As relações de trabalho são informais e violentas, sem respeito aos direitos humanos, sendo o processo de trabalho de caráter insalubre e penoso. A exploração do trabalho infantil precisa ser contraposta mediante ações efetivas de amparo e desenvolvimento social.

As relações humanas, o papel social e econômico do trabalho na vida das famílias e das comunidades, são questões agudas para esses grupos sociais. Além dos problemas decorrentes das condições de moradia, há ainda uma diversidade dos relacionados com a atividade produtiva, tais como acidentes traumáticos e por mordeduras de cobra; doenças relacionadas à transmissão vetorial e doenças relacionadas à poluição ambiental (fumos e gases), todos requerendo atenção especial do sistema de saúde.

O impacto ambiental da atividade extrativista se faz presente com devastação vegetal e comprometimento dos aqüíferos da Chapada do Araripe, ampliando a escassez de água do semiárido nordestino.
A ausência de uma política pública reorganizadora do processo de captação, do armazenamento e da distribuição das águas na região, cuidadora da preservação de sua qualidade, é grandemente responsável pela pressão sócioambiental sobre a condição de saúde das populações que vivem nessa região e em particular do povo da floresta. Ficou evidente que o sistema de vigilância da qualidade das águas (VIGIÁGUA) não alcança as comunidades rurais da Floresta do Araripe e de seu entorno.

Os dados obtidos por intermédio da metodologia adotada foram consistentes e podem ser utilizados na produção de indicadores para a vigilância da saúde, no contexto da Chapada do Araripe. A realidade empírica observada e analisada pela percepção do conjunto dos interlocutores participantes, e ressignificada à luz dos marcos teóricos adotados, permitiu um processo de integração (síntese) em torno das categorias-chave (figuras geradoras). Este método mostrou-se adequado para revelar a enorme diversidade de situações nocivas a que está exposta a população que vive da floresta, as quais determinam as precárias condições de vida e de saúde. Em adição, foi possível compreender como estas condições pressionam o bioma, vulnerabilizando a floresta do Araripe em termos de preservação de sua biodiversidade.

Outros estudos são requeridos para aprofundar este tema e para subsidiar ações de melhoria na qualidade de vida da população e do ambiente da floresta. A preocupação deve ser em auxiliar a intervenção, organização e articulação de grupos e redes sociais de apoio, a fim de buscarem mudanças efetivas para as situações e problemas encontrados, destacando-se as questões de gênero e inter-gêneros nesse contexto. 


\section{Resumo}

São apresentados resultados parciais de estudo para elaboração de modelagem de vigilância da saúde de grupos humanos que vivem do extrativismo vegetal na Floresta Nacional da Chapada do Araripe, Ceará, Brasil. Como principais justificativas do estudo tem-se a importância desta Floresta Nacional para a preservação da qualidade da vida na região do semi-árido nordestino e o contexto de vulnerabilidades das florestas brasileiras. A abordagem metodológica é de um processo coletivo de compreensões integradas relacionadas à subjetividade dos sujeitos em face do ambiente produtivo na floresta, incluindo questões de gênero. O estudo apontou resultados diversos, alguns já previsíveis, outros surpreendentes, do ponto de vista da visibilidade de questões presentes no cotidiano das populações que trabalham e vivem da floresta.

Vigilância da População; Saúde Ambiental; Ecosistema

\section{Referências}

1. Tambellini AT, Câmara V. A temática da saúde e ambiente no processo de desenvolvimento do campo da saúde coletiva: aspectos históricos, conceituais e metodológicos. Ciênc Saúde Coletiva 1998; 3:47-59.

2. Minayo MCS, Miranda AC, organizadores. Saúde e ambiente sustentável: estreitando nós. Rio de Janeiro: Editora Fiocruz; 2002.

3. Augusto LGS. A construção de indicadores em saúde ambiental: desafios conceituais. In: Minayo MC, Miranda AC, organizadores. Saúde e ambiente sustentável: estreitando nós. Rio de Janeiro: Editora Fiocruz; 2002. p. 291-312.

4. Augusto LGS, Florêncio L, Carneiro, RM, organizadores. Pesquisa (ação) em saúde ambiental: contexto, complexidade - compromisso social. Recife: Editora Universitária da Universidade Federal de Pernambuco; 2001.

5. Augusto LGS, Carneiro RM, Martins PH, organizadores. Abordagem ecossistêmica em saúde: ensaios para ao controle do dengue. Recife: Editora Universitária da Universidade Federal de Pernambuco; 2005 .

6. Santos M. Espaço e método. 3a Ed. São Paulo: Editora Nobel; 1992.

7. Martins PH, Fontes B, organizadores. Redes sociais e saúde: novas possibilidades teóricas. Recife: Editora Universitária da Universidade Federal de Pernambuco; 2004.

\section{Colaboradores}

Este é um artigo de resultados de pesquisa levada a cabo pelas duas autoras. Ambas trabalharam conjuntamente na redação do artigo.

\section{Agradecimentos}

Para Antônia Mendes de Araújo, auxiliar de pesquisa, e para Beatriz Gomes Luna, pelo trabalho de campo.
8. Samaja J. A produção social e a saúde: elementos metodológicos sobre a questão das relações entre saúde e condições de vida. Salvador: Casa da Qualidade Editora; 2000.

9. Teixeira CF. O futuro da prevenção. Salvador: Casa da Qualidade Editora; 2001.

10. Fundação Nacional de Saúde. Vigilância ambiental em saúde. Brasília: Fundação Nacional de Saúde; 2002.

11. Leff E. Epistemologia ambiental. São Paulo: Cortez Editora; 2001.

12. Fundação de Desenvolvimento Tecnológico do Cariri. Plano de gestão da APA - Área de Proteção Ambiental da Chapada do Araripe. Recife: Secretaria de Ciência, Tecnologia e Meio Ambiente; 1998.

13. John L. Direito de acesso à água. http://www. estadao.com.br (acessado em 29/Ago/2006).

14. Brasil. Lei no. 9.433, de 08 de janeiro de 1997. Institui a Política Nacional de Recursos Hídricos, cria o Sistema Nacional de Gerenciamento de Recursos Hídricos, regulamenta o inciso XIX do art. 21 da Constituição Federal, e altera o art. 1o da Lei no. 8.001, de 13 de março de 1990, que modificou a Lei no. 7.990, de 28 de dezembro de 1989. Diário Oficial da União 1997; 8 jan.

15. Mateos SB. Quem explora a mão-de-obra infantil. Revista Atenção 1996; 2:9-16.

Recebido em 02/Mai/2006

Versão final reapresentada em 19/Abr/2007

Aprovado em 20/Abr/2007 